\title{
Assessing the Role of Plants in International Manufacturing Networks: A Tool to Monitor the Strategic Alignment
}

\author{
Donatella Corti, Luca Canetta, and Alessandro Fontana \\ University of Applied Sciences and Arts of Southern Switzerland, ISTePS, Manno, Switzerland \\ \{donatella.corti, luca.canetta, alessandro. fontana\} @supsi.ch
}

\begin{abstract}
The internationalization of operations has been quite a common trend for Western companies over the last 20 years. The development of manufacturing networks is a more and more common solution also for SMEs. In order to make sure that the whole network evolves according to the business requirements, each single plant needs to be assigned a precise role. Starting from the well-known framework proposed by Ferdows ([5]; [6]) on the strategic role of plants, a tool is developed to monitor the role of production plants by aligning the vision of the headquarters and the one of the plant itself. Four case studies are carried out to validate the model and some guidelines are then derived to interpret the output. This paper contributes to the field dealing with the strategic role of plants with a proposal that can be easily applied by practitioners.
\end{abstract}

Keywords: manufacturing networks, strategic role of plants, Ferdows' model, assessment model.

\section{Introduction}

Over the last decades, it has been a common trend for a large number of companies in industrialized countries to increase their international presence as a way to strengthen competitive position and increase their sustainability in the long term. Even though in the past this choice was mainly confined to multinational enterprises, nowadays production relocation is a more and more widespread option also for SMEs (see for example [3]). The recent evolution of the competitive context and, in particular, the huge economic crisis that hit the Western countries led to new trends for this phenomenon: as argued by Kinkel ([9]), production relocation has declined, whilst the number of backshoring activities has remained stable in the period 2007 to mid-2009. At the same time, a further relocation from East Europe to Far East has been noted ([9]). As shown by these recent findings, the research on international production networks is still an evolving topic that needs to keep pace with the dynamics of the macroeconomic environment. The academic interest for management of operations in offshored plants has increased and shifted from dyadic relationships to the networks framing and management ([11]; [8]; [7]; [6]). In this paper the focus is on a specific form of direct foreign investment that entails the set up of a fully owned plant by a

B. Grabot et al. (Eds.): APMS 2014, Part III, IFIP AICT 440, pp. 360-367, 2014.

(C) IFIP International Federation for Information Processing 2014 
SME running a dispersed production network. In this context, attention is paid to the coordination of the network from a strategic point of view: companies need tools that could support them in continuously monitoring the configuration of the network and, in particular, if and how the single plant is contributing to the success of the network as a whole. The proposed model is a decisional supporting tool that aims at supporting SMEs in continuously monitoring the dynamics of the production network by making sure that each plant is acting according to the assigned role. The tool provides managers of both the parent company and the offshored plant with a common set of data to start sharing a strategic vision the running of the plant should be based on. This paper contributes to the literature debate by further testing the Ferdorws' model, whilst, at the same time, attempts to translate theoretical concepts currently mainly used only in the academic arena into a tool for practitioners.

\section{The Strategic Role of Plants within an International Production Network}

The literature on manufacturing networks mainly takes a macro and static perspective ([14]), neglecting the dynamics and lacking overall evidence on the interactions between the evolution of individual plants and the whole network ([2]). Although there are several models in defining strategic roles of the international network plants, the Ferdows's model ([5]; [6]) be considered as a milestone or a starting point for the development of a tool which enables the consideration of dynamic changes of a plant's role [10]. [6] addresses the roles of plants, introducing a model based on a matrix whose axis represent the strategic reason for choosing the location of a plant and the site's competence (measured on a low to high scale). Crossing the two dimensions, six strategic roles are identified. Unlike other classifications, the Ferdow's one introduces a clear analytical framework and allows the consideration of some dynamic aspects. He also pursued a more operations management-oriented approach focusing on the role and functioning of individual factories in international manufacturing networks rather than using the business unit as unit of analysis [10]. [16] state that the contribution of plants which have "low" level in the vertical axis of the Ferdows' model is to produce items, while "high" level in the vertical axis represents also important developments such as providing know-how for the other facilities of the network. However, the Ferdows' model lacks of a clear definition and operationalization of the site competence dimension [15]. Building on this reasoning, [10] have focused on the dynamic changes that occur in the strategic roles of factories and enhanced the site competences axis of Ferdows' conceptual model by identifying additional factors that contribute to the level of site competence. Different plants are source of different capabilities [4]: companies should work on the assessment of the plant's operations and performance management of single plants. Some possible indicators to be used are mentioned in [12] or [4]. Even though the importance of monitoring the network considering the different role of each plant within it, literature on the assessment of international production networks is still scarce and lacks of holistic frameworks. 


\section{An Assessment Model to Support the Strategic Role of Plants}

This paper aims at contributing to the literature on strategic roles of plants by proposing a model that further extend Ferdows' proposal ([6]) by taking into account its recent extensions ([10]; [15]) and making it suitable for practitioners'use. Practical tools are needed to make sure, on the one hand, that strategic objectives are properly shared between the headquarters and each single manufacturing plant and, on the other hand, that performance of plants are aligned with the evolution of the network as a whole. The goal is to provide a dashboard (Figure 1) for both headquarters and foreign plants that can be used to determine the strategic role of the specific production unit of interest. This is done through mapping the current strategic role from the perspective of both headquarter and the plant itself and by analyzing possible gaps in order to build a shared set of believes. Furthermore, since the role of plants within the network is a dynamic one, the model is also able to timely highlight the need for a possible shift. The proposed model takes as a reference the two dimensions characterizing both Ferdows' and Meijboom and Vos's model, but the vertical axis (site competence) is redefined considering the current needs of the international production networks. The resulting framework becomes a tool that could be used to position different plants and monitor their role over time identifying possible misalignments. The tool includes kind of a dashboard that shows the results in a graphical way and a questionnaire that supports practitioners to define in a structured way the role of the plant. Since one of the aim of this tool is the measurement of how aligned are the perspectives of headquarter and foreign plants, the application procedure foresees the use of the same set of questions for both the parent company and the plant. By comparing the two resulting positioning it is possible to take into account possible misalignment characterizing the two visions. The present version of the model has been developed with Excel that provides the user with an immediate representation of the results that makes easier the comparison between the two visions. Like in the reference models, the key aspects to be investigated are: "Primary strategic reason for the location of the plant" and "Level of site competence \& technical activities at the plant".

\section{Primary strategic reason for the location of the plant}

The main strategic reasons for opening a plant in a specific location are the three already proposed by [6], as also further confirmed by more recent researches, namely access to low cost production input factors, use of local technological resources and proximity to market. A first set of questions has been included in the tool to understand which factors have a stronger effect on the choice of the location for the plant. With a straightforward calculation considering all the factors and their relative importance, the main strategic reason is determined. For each strategic reason a set of related factors are identified and who fills in the questionnaire has to rank their relative importance on a 5-point scale ( $1=$ unimportant; $5=$ very important). The total score for the single factor is then translated into a percentage that reflects the level of pursuing of that objective. More objectives are achieved at the same time, but one is the main trigger for setting up the plant. The strategic reason with the highest 
probability is defined as the primary reason for the relocation. The complete list of elements is shown on the left side of Figure 1.

\section{Level of site competence \& technical activities at the plant}

This dimension takes into consideration the site competence meaning the level of responsibility and autonomy assigned to the plant. Some changes compared to the list of activities proposed in [10] have been introduced and a total of 10 dimensions have been identified to characterize this axis. The choice of the dimensions has been driven by both literature analysis and expertise of authors in the fields of global operations management. In order to operationalize the framework each factor has been assigned equal importance $(10 \%)$. The higher the percentage achieved by a plant, the more strategic its role is. In order to calculate the level of site competence expressed in percentage ( $100 \%$ means the highest strategic role), each one of the ten factors is analyzed by considering its constituting elements associated to the questions included in the questionnaire. Activities are presented in order of increasing importance so that the higher the number of elements included, the more strategic the role is.

\begin{tabular}{|c|c|c|c|}
\hline \multicolumn{4}{|c|}{ STRATEGIC ROLE ASSESSMENT MODEL FOR MANUFACTURING PLANTS } \\
\hline Primary Strategic Reason for the Location of the Plant & & Innovation and introduction of new products \& processes for the entire company & \\
\hline Access to low-cost production input factors & \multirow{10}{*}{ 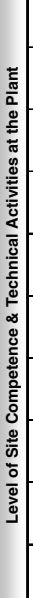 } & Plant is capable of creating new products \& processes for the entire company & \\
\hline $\begin{array}{l}\text { - Low-cost labor } \\
\text { : Raw materials } \\
\text { - Energy }\end{array}$ & & $\begin{array}{l}\text { Collaboration with centers of knowledge } \\
\text { Plant collaborates with universities, research centers (governmental / independent), labs and other } \\
\text { institutions }\end{array}$ & \\
\hline $\begin{array}{l}\text { : Key suppliers } \\
\text { Capital }\end{array}$ & & $\begin{array}{l}\text { Investments in technical and managerial resources } \\
\text { Plant invests in acquiring and maintaining local resources, and building on technical know-how }\end{array}$ & \\
\hline Use of local technological resources & & $\begin{array}{l}\text { Product customization } \\
\text { Plant carries out complicated product development and customization }\end{array}$ & \\
\hline $\begin{array}{l}\text { - Local technical know-how } \\
\text { : Skilled labor force } \\
\text { - Advanced infrastructure }\end{array}$ & & $\begin{array}{l}\text { Complicated process changes \& reengineering } \\
\text { Plant carries out complicated process development and process reengineering }\end{array}$ & \\
\hline & & $\begin{array}{l}\text { Minor modifications in products \& processes } \\
\text { Plant makes minor modifications and developments in products \& processes }\end{array}$ & \\
\hline & & $\begin{array}{l}\text { Production planning } \\
\text { Plant is responsible for planning the production }\end{array}$ & \\
\hline $\begin{array}{l}\text { Proximity to market } \\
\text { Proximity to important markets } \\
\text { Proximity to key customers }\end{array}$ & & $\begin{array}{l}\text { Procurement autonomy } \\
\text { Plant has autonomy in terms of procurement }\end{array}$ & \\
\hline $\begin{array}{l}\text { - Access to tax benefits } \\
\text { - Euicker and more reliable distribution } \\
\text { Easier customization of products }\end{array}$ & & $\begin{array}{l}\text { Production scheduling } \\
\text { Plant is responsible for scheduling the production }\end{array}$ & \\
\hline & & $\begin{array}{l}\text { Production } \\
\text { Plant carries out mainly production activities }\end{array}$ & \\
\hline
\end{tabular}

Fig. 1. Dashboard presenting the assessment scope and factors

Even though the list of proposed factors is partially overlapping with the one introduced by [10], some changes have been introduced in order to take into account recent literature on both operations management and global production networks. For instance, it has been considered important to make explicit the possible ability of a plant to customize products. On the one hand, the need to customize is aligned with recent trends of production paradigms (see for example [13], [1]) that are influencing also markets under development. At the same time, from the production point of view, the customization requires a higher level of autonomy for the management of processes. Also the factor "collaboration with center of knowledge" has been introduced in order to consider the closer and closer link between companies and research 
centers whenever the introduction of innovation requires important investments as well as cutting edge knowledge. The ten activities use to define the level of site competence are the following (for space constraints they are not detailed further):

- $\quad$ Production (1)

- Production scheduling (2)

- Procurement autonomy (3)

- Production planning (4)

- Minor modifications in products \& processes (5)

- Complicated process changes \& reengineering (6)

- $\quad$ Product customization (7)

- Investments in technical and managerial resources (8)

- Collaboration with centers of knowledge (9)

- Innovation and introduction of new products \& processes for the company (10)

In Figure 1, the right side of the framework highlights the list of factors and the cumulative probability that determines the level of site competence. In order to determine the percentage of attainment of a certain competence is carried out following a similar reasoning than the one used for the strategic priority. For each competence a list of factors is assessed on a 5-point scale and then it is translated in to a percentage value between 0 and 10 in such a way that the ten factors can score a maximum of $100 \%$ (the highest strategic role). The availability of a tool allowing a practical and systematic identification of the strategic role of plants and the observation of its evolution over time is recommendable for every manufacturing network, in particular for those run by SMEs that typically have a less structured monitoring system in place and have fewer resources to dedicate to this task.

\section{Empirical Validation}

The proposed assessment tool has been validated collecting empirical data from a sample of four Turkish companies running an international production network. The main selection criteria has been the location of the headquarter, Turkey, in order to avoid possible bias due to cultural differences in managing the network. Out of the nine companies that have been contacted, four have shown positive interest to take part in the case study research by answering the questionnaires and carrying out face-to-face interviews. One of the sampled companies is a big one even though the proposed assessment has as primary beneficiary SMEs. This case has been used to further check that the tool is coherent with already existing procedures in place in multinational and big companies. According to the aim of the assessment model, for each company both the headquarters and one plant of the network located in a foreign country have been involved in the research. Main features of the sampled companies are summarized in Table 1. The use of the tool allowed the assessment of the vision of the headquarters and the one of the production plant. To give an example of the output the tool can provide, the case of company $\mathrm{C}$ is discussed. The questionnaire has been filled in separately by the supply chain manager of the headquarters and the plant manager of the plant located in Russia. The analysis carried out by both the headquarters and the plant 
led to the identification of "proximity to market" as the primary reason for locating the plant: in both cases, this strategic reason was the highest ranked with respectively 26,7 $\%$ (plant, Figure 2) and 28,9\% (headquarters, Figure 2).

Table 1. Summary of information for the analyzed sample

\begin{tabular}{|c|c|c|c|c|c|c|}
\hline & Sector & Turnover & $\begin{array}{c}\text { No. } \\
\text { plants }\end{array}$ & $\begin{array}{c}\text { Analyzed } \\
\text { plant }\end{array}$ & $\begin{array}{c}\text { No. em- } \\
\text { ployees } \\
\text { (total) }\end{array}$ & $\begin{array}{c}\text { No. em- } \\
\text { ployees } \\
\text { (plant) }\end{array}$ \\
\hline A & $\begin{array}{c}\text { Fabricated steel } \\
\text { production }\end{array}$ & $\begin{array}{c}100-500 \\
\text { Mln }\end{array}$ & 3 & China & 2400 & 270 \\
\hline B & Beer production & $>1$ billion & 16 & Russia & 10000 & 4500 \\
\hline C & Building products & $\begin{array}{c}100-500 \\
\text { Mln }\end{array}$ & 3 & Russia & 220 & 80 \\
\hline D & Construction & $<100$ Mln & 3 & Russia & 900 & 200 \\
\hline
\end{tabular}
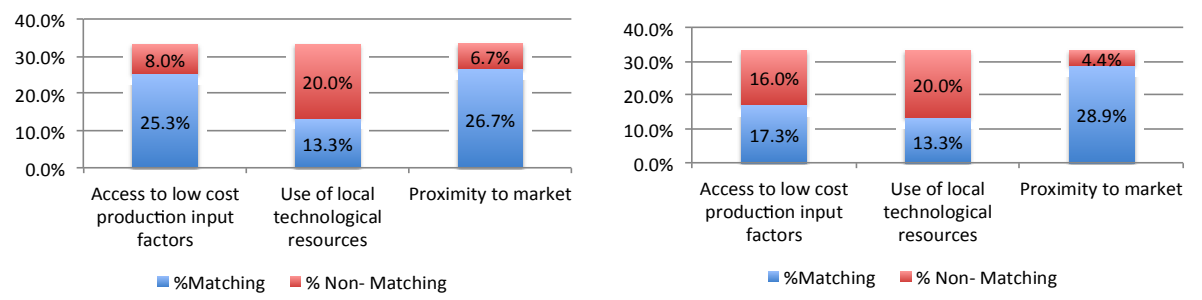

Fig. 2. Company C- Russian plant: assessment of $\%$ of matching with reasons according to the primary strategic reason (left: vision of the plant; right: vision of the headquarter)

This strategic reason has been also confirmed by the open interview that was carried out with the headquarter managers to interpret and validate the tool's results. Moving to the site competence, the overall score obtained from the headquarters is $59 \%$ out of a possible score of $100 \%$, whereas the score assigned by the plant itself is noticeably higher and equal to $83 \%$. This can be interpreted as the plant seeing itself as more strategically important than the headquarters views it. It is worth noticing that the plant is a new one, set up in 2010: it could take some time to fine-tune the management of a plant and, in the first of operation, misalignment are likely to happen. Being able to highlight such gaps timely is a way to achieve a better level of integration since the beginning with a positive impact not only on the single plant, but also on the network profitability. The fact that the plant identify a higher level of competence probably means that the headquarters are not fully aware yet of the full potentialities of the plant. The identification of the main gaps between the two visions provides the headquarters with some valuable inputs to improve the management of the plant. A more detailed analysis should be carried out to understand the sources of the biggest differences appeared in the activities "Complicated process changes \& reengineering", "product customization" and "Innovation and introduction of new products \& processes for the entire company". 


\section{Managerial Guidelines When Using the Tool}

For the proposed tool to be easily accepted and put into use by executives, it has been designed as a self-evaluating tool, based on a set of simple and straightforward questions that graphically visualize the obtained results for facilitating their interpretation. As shown in the case study analysis, the tool allows highlighting possible gaps. At this point, it is important to be able to point out the difference, analyze it further to find the root cause and to take actions to increase the alignment. Some guidelines have been drawn to interpret the results of the tool. When the primary reason does not coincide between the two visions an important intervention is foreseen in order to realign the strategy, this entails a significant strategic change for at least one of the involved actors. On the contrary, a gap highlighted in the site competence could be confined to single activities that typically require interventions of a practical nature. In the case of a misalignment in terms of the current primary location driver, in order to quickly and objectively evaluate the scores the developed guidelines suggest the following actions:

- $\quad$ organization of a meeting involving managers from the headquarter and the plant;

- $\quad$ investigation of the most important causes or areas of misalignment;

- information should be shared, if necessary, in order to align the perceptions

The gap or the misalignment about the site competences between the two viewpoints can arise from three possible scenarios:

- the headquarters has a realistic view of the plant, but the plant either overestimates or underestimates its current competence level.

- the plant has a realistic view of itself, but the headquarter either overestimates or underestimates the current competence level of the plant.

- the headquarter and the plant have extreme views of the plant, one underestimating whereas the other overestimating.

The developed guidelines suggest different approaches to be adopted depending on the magnitude of the gap. For differences up to 5\% no important intervention is foreseen. For gaps between $5 \%$ and $10 \%$ the situation is more serious and a careful analysis of factors for which the gap is higher is needed since there is a clear misalignment for some activities. For gaps higher than $10 \%$, the intervention of the headquarters is urgent to limit the derivation of the two visions. Possible interventions depend on contingent factors thus making difficult the development of a general procedure.

\section{Conclusions}

The model proposed in this paper is a tool meant to support a company not only in identifying the role of a plant, but also to understand whether the same vision is shared by both the plant and the headquarter. The main benefit for the plant managers is that they will be able to better evaluate the strengths of the plant as well as major areas that may provide opportunities for future improvements. On the other hand, the headquarters will have a better picture of the whole network that should result in a 
more balanced set of actors. Additional empirical data collection is needed to further validate and fine-tune the tool. An extension of the model is already under development that introduces a more detailed assessment model including a set of indicators for the different factors defining the site competence.

\section{References}

1. Boër, C.R., Pedrazzoli, P., Bettoni, A., Sorlini, M.: Mass Customization and Sustainability. An assessment framework and industrial implementation. Springer (2013)

2. Cheng, Y.C., Farooq, S., Johansen, J.: Manufacturing network evolution: a manufacturing plant perspective. International Journal of Operations and Production Management 31(12), 1311-1331 (2011)

3. Corti, D., Egana, M.M., Errasti, A.: Challenges for off-shored operations: findings from a comparative multi-case study analysis of Italian and Spanish companies. In: Proceedings of 16th Annual EurOMA Conference, Gothenburg (2009)

4. Dossi, A., Patelli, L.: You Learn From What You Measure: Financial and Non-Financial Performance Measures in Multinational Companies. Long Range Planning 43, 498-526 (2010)

5. Ferdows, K.: Mapping international factory networks. In: Ferdows, K. (ed.) Managing International Manufacturing, Elsevier, Amsterdam (1989)

6. Ferdows, K.: Making the most of Foreign Factories. Harvard Business Review (MarchApril 1997)

7. Forsgren, M., Holm, U., Johanson, J.: Managing the embedded multinational: A business network view. Edward Elgar, Cheltenham (2005)

8. Ghoshal, S., Bartlett, C.A.: The multinational corporation as an inter-organizational network. In: Ghoshal, S., Westney, D.E. (eds.) Organization Theory and the Multinational Corporation, pp. 68-92. Palgrave MacMillan, Houndsmill (2005)

9. Kinkel, S.: Trends in production relocation and backshoring activities. Changing patterns in the course of the global economic crisis. International Journal of Operations \& Production Management 32(6), 696-720 (2012)

10. Meijboom, B., Vos, B.: Site competence dynamics in international manufacturing networks: instrument development and a test in Eastern European factories. Journal of Purchasing \& Supply Management 10, 127-136 (2004)

11. O'Donnel, S.: Managing Foreign Subsidiaries: Agents of Headquarters, or an Interdependent Network? Strategic Management Journal 21, 525-548 (2000)

12. Parthiban, P., Goh, M.: An integrated model for performance management of manufacturing units. Benchmarking: An International Journal 18(2), 261-281 (2011)

13. Piller, F.T.: Observations on the present and future of mass customization. International Journal of Felxible Manufacturing Systems 19(4), 630-636 (2007)

14. Rudberg, M., Olhager, J.: Manufacturing networks and supply chains: an operations strategy perspective. Omega: International Journal of Management Science 31, 29-39 (2003)

15. Vereecke, A., Van Dierdonck, R.: The Strategic Role of the Plant: Testing Ferdow's Model. International Journal of Operations \& Production Management 22(5), 492-514 (2002)

16. Vereecke, A., De Meyer, A., Van Dierdonck, R.: The Strategic Role of the Plant in International Networks: A Longitudinal Study. Vlerick Leuven Gent Working Paper Series (July 2008) 